\title{
The octopus in the laboratory. Handling, maintenance, training ${ }^{1}$
}

JOSEPH I. WALKER, UNIVERSITY OF SOUTH FLORIDA, Tampa, Florida 33620, NICHOLAS LONGO, COLGATE UNIVERSITY, Hamilton, New York 13346, and M. E. BITTERMAN, BRYN MAWR COLLEGE, Bryn MaWr, Pennsylvania 19010

Octopus maya lives well for long periods in a small tank containing a plastic house in which it can be carried without disturbance to and from an experimental situation. Data are reported on the growth of animals kept under these conditions as a function of feeding schedule and on their food intake as a function of deprivation. Some animals were trained in a runway with food as reward, and others were trained in a simple maze with return to sea water as reward.

\section{HANDLING AND HOUSING}

If, for comparative purposes (Bitterman, 1965), one sets out to study the octopus in situations analogous to those used for the study of learning in higher animals, the first difficulty that is encountered stems from the resistance of the octopus to being moved, either by hand or with a net, from its living tank to an experimental apparatus. Sutherland and Muntz (1959) did not find satisfactory performance in their animals, even when they permitted half an hour to elapse between the transfer and the start of training "to overcome the trauma of being moved," and they concluded that moving the octopus was not feasible. Maldonado (1968) recently has reported being able to work with octopuses $1 \mathrm{~h}$ after they have been moved from their living tanks to his apparatus, but to have to wait for an hour substantially limits the amount of data that can be collected unless several sets of apparatus are available (Maldonado uses 14!). Furthermore, the fact that it is necessary to wait for so long a time suggests that Maldonado's method of handling must create considerable disturbance.

An alternative to moving the octopus is to bring the training apparatus to the living tank, which is feasible only when the apparatus is not very elaborate. The most widely employed training method is simply to present a stimulus (visual or tactual) at the end of a rod or a line held in the hand, and to reward the octopus for approaching or for grasping the stimulus with a bit of fish attached to the end of another rod, or to punish the octopus for making the response by shocking it with a pair of electrodes attached to the end of yet another rod (see, for example, Muntz. Sutherland, \& Young, 1962; Parriss, 1963: Wells, 1964a; Young, 1965). This method certainly does not require much in the way of apparatus, but it is rather unsatisfactory on other grounds. Control of the stimulus is inadequate, the definition of response is uncertain, and the delay of reinforcement is considerable. ${ }^{2}$ To bring somewhat more sophisticated equipment to the living tank, such as a motor-driven stimulator (Sutherland, 1957) or an automatic feeder that is triggered by an objective response detector (Coates, Hussey, \& Nixon, 1966), is cumbersome. Then, too, there is the disadvantage that, if the training is done in the living tanks, they must be placed a considerable distance apart to prevent work with one $S$ from influencing others. A second alternative to moving the octopus is to have it live in the training situation (Maldonado, 1963; Wells, 1964b), which requires one set of apparatus for each animal being studied at any given time.

Fortunately, a way now has been found to move the octopus without disturbance from its living tank to a training situation. The method was suggested by work with the goldfish (Potts \& Bitterman, 1968). The living tank of the octopus is equipped with a plastic house in which the animal lives and in which it may be carried about the laboratory. A critical feature of the method is that the width of the house and the width of the tank are approximately the same.

Our work was done at the Estacion de Biologia Pesquera in Campeche, Mexico, with Octopus maya, a species from the Bay of Campeche recently described by Voss and Solis-Ramirez (1966). The animals are caught easily in unbaited earthenware pots (illustrated in Fig. 1) that are set out on lines and in which the animals come to live. In the laboratory, houses made of $1 / 4$-in. gray Plexiglas (illustrated in Fig. 1) are substituted for the pots. Each house is $17.5 \mathrm{~cm}$ wide, $17.5 \mathrm{~cm}$ deep, and $21 \mathrm{~cm}$ high (outside dimensions). The top of the house is cut back, and slots are milled in the sides to hold a Plexiglas door that can be inserted whenever the octopus must be confined in the house as, for example, during weighing. For most purposes, the door is unnecessary because the animal remains in the house when being carried. Several rows of small holes may be drilled in the bottom and in the back wall of the house to permit water to run out of the house when it is lifted from the living tank. Emptied of water, the house is easier to carry. That the octopus is not disturbed by
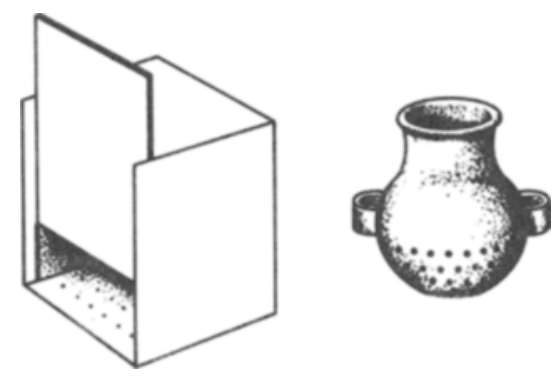

Fig. 1. Octopus chambers. At left is a Plexiglas house (17.5 cm wide) used in the laboratory, while at right (drawn to the same scale) is an earthenware pot in which the animal is caught.

being without water for a few seconds is evidenced by the fact that an animal which has been habituated to the laboratory will attack crabs immediately after having been carried for the first time in such a house from its living tank to a feeding chamber. ${ }^{3}$ The holes may, however, be omitted, because the house is not terribly heavy even when filled with water.

The individual living tanks are shown in Fig. 2. They are made by partitioning a larger wooden tank, the inside dimensions being $100 \times 50 \times 50 \mathrm{~cm}$, into five smaller tanks that are about $18 \times 50 \times 50 \mathrm{cn}$ high. The larger tank is fitted with a hinged lid made of plastic screening stretched over a wooden frame. ${ }^{4}$ The individual tanks are

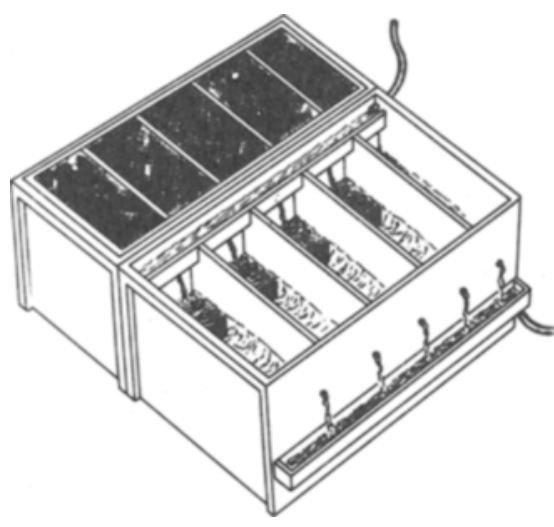

Fig. 2. Living tanks. The drawing shows two large tanks $(100 \times 50 \times 50 \mathrm{~cm})$, one with a mesh cover. Each is divided into five individual compartments. The position of the Plexiglas house in each compartment is shown. Sea water is brought into a common trough, which feeds five units, through an inlet tube (upper right) and runs back to the sea by way of a common outlet trough and tube (lower right). 


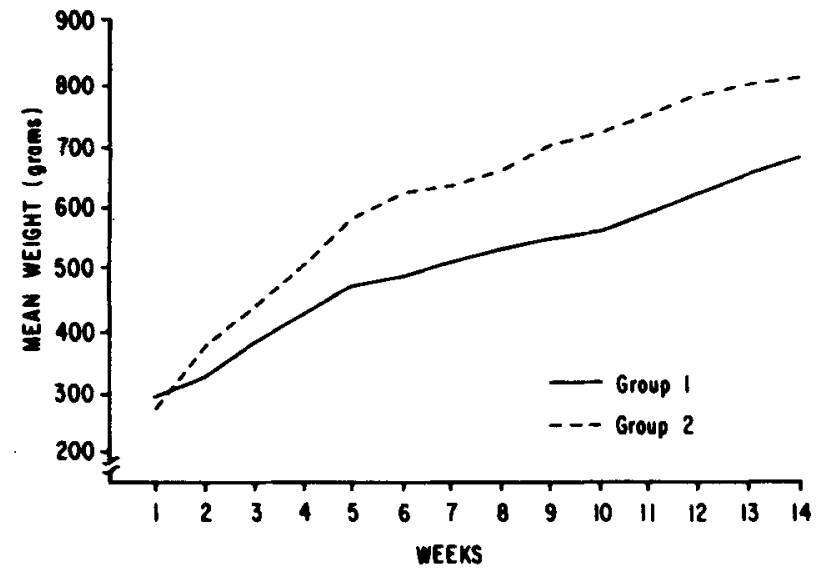

Fig. 3. The weekly mean weights of two groups of octopuses fed each day according to different schedules (one vs two crabs per $50 \mathrm{~g}$ of body weight).

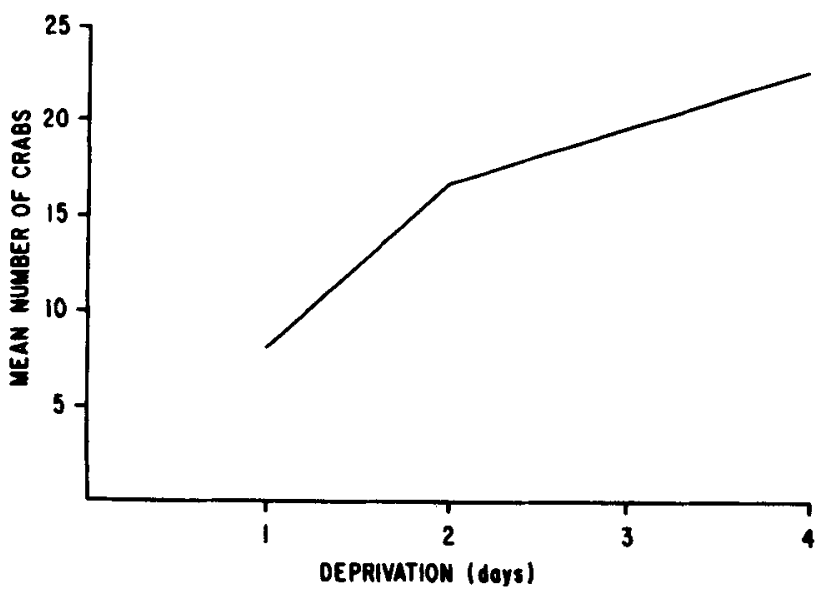

Fig. 4. Mean number of crabs required to satiate a group of octopuses as a function of the number of days without food since a previous feeding to satiation. completely isolated from each other. Each has its own sea-water inlet (an opening in a trough serving all five units), through which the water splashes into each unit at the rate of about .75 liters $/ \mathrm{min}$, and its own retum to a common outlet trough that maintains the water level at about $25 \mathrm{~cm}$. An open system of circulation is used, water being pumped from the bay into a large settling tank on the roof of the laboratory and run by gravity through the living tanks back to the bay. The position of the plastic house in each unit also may be seen in Fig. 2. To move an animal that is in its house, one has only to lift the house from the water, tilting it backward at the same time. If the animal is out of its house-a relatively rare occurrence-the house simply is moved forward until the animal enters and then lifted. Since the width of the house is approximately that of the living tank, there is no place else for the animal to go as the house is moved forward.

\section{FOOD INTAKE, GROWTH, AND SATIATION}

The octopus adapts readily to these conditions, although the living tanks are considerably smaller than those traditionally used. Our animals begin to take food 2 or 3 days (and sometimes only a few hours) after capture, and they grow steadily. Figure 3 shows the growth of two groups of animals that had a mean weight of about $300 \mathrm{~g}$ at the beginning of the experiment and which were weighed each week thereafter for 3 months while they were maintained on two different feeding schedules. Four animals in Group 1 were fed one small crab per $50 \mathrm{~g}$ of body weight (as determined at the beginning of the week) each day, while five animals in Group 2 were fed two crabs per $50 \mathrm{~g}$ of body weight each day. The crabs (Uca rapax), which had a mean gross weight of $4.1 \mathrm{~g}$, were given in the early aftemoon, and the tanks were cleaned early the next morning. For all practical purposes, the animals of Group 2 were fed on an ad lib schedule, because none of them consistently finished all the crabs given. Our results for Octopus maya agree well with those of Nixon (1966) for Octopus vulgaris, which she found to gain about $5 \mathrm{~g}$ per day with abundant feeding.

In preparation for instrumental experiments with food as reward, we collected the data plotted in Fig. 4. The curve shows the mean number of $4-g$ crabs required to satiate $400-\mathrm{g}$ octopuses deprived of food for 1-4 days. Our method was simply to drop a crab a few inches away from the animal and to observe whether or not it took the crab. The interval between crabs was $1 \mathrm{~min}$, and the criterion of satiation was the failure of the animal to take two crabs. Some of the animals would remain in their houses as the session began, reaching out or coming out for each crab, and then withdrawing once more. Others would wait for crabs outside their houses in the early part of the session, especially when they had been deprived for several days, and return to their houses later in the session, taking additional crabs from there. At length, all animals would stop taking crabs.

After repeated daily satiations to test the reliability of the method and to establish a feeding rhythm, the formal experiment was begun. Each of 12 animals was satiated at intervals of 1,2 , and 4 days in balanced order, with two animals assigned at random to each of the six possible orders. As Fig. 4 shows, the mean number of crabs eaten increased $(p<.01$ by a simple ranking test) as a positive growth function of the deprivation interval. It

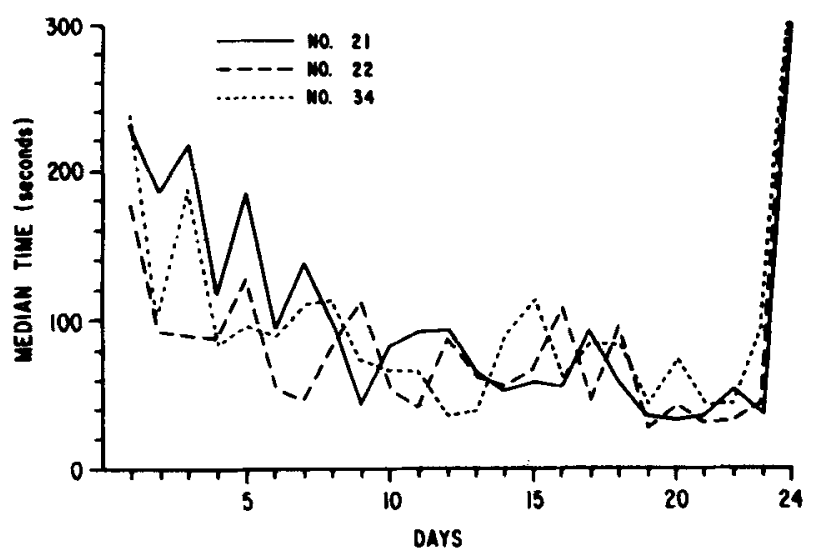

Fig. 5. Runway acquisition curves for three octopuses plotted in terms of median time per trial. On the 24th day, all three animals failed to perform and soon thereafter began to produce eggs. 


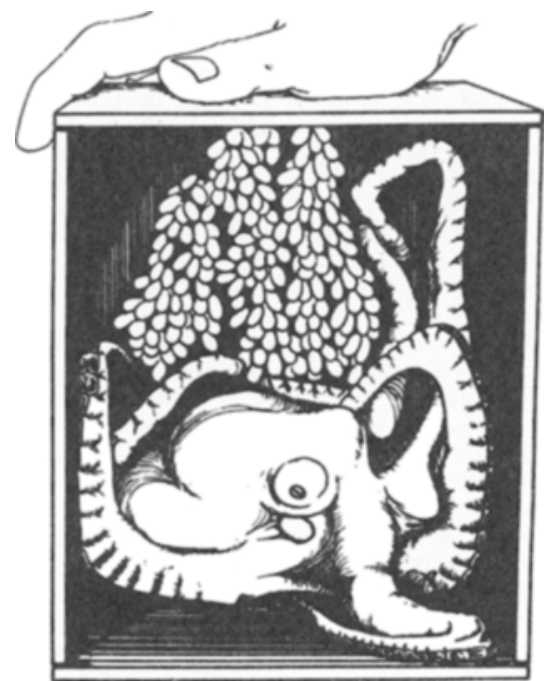

Fig. 6. A female in a plastic house with several clusters of eggs.

should be noted that the data plotted include the two criterion crabs, which remained in the tank and were eaten sometime between the termination of the session and the cleaning of the tank early the next morning; the number of crabs attacked during the session is in each case two less. The results of a comparable experiment with the African mouthbreeding fish, Tilapia macrocephala, are reported elsewhere (Bitterman, Wodinsky, \& Candland, 1958).

\section{TRAINING IN RUNWAY AND MAZE}

A traditional mammalian training situation that seems perfectly appropriate for octopuses is the runway. Shown in Fig. 5 are the acquisition curves of three females trained in a wooden runway of the same dimensions as the individual living tanks, except that it was $1.5 \mathrm{~m}$ long. A window of clear Plexiglas was set into the goal end. After 2 weeks of habituation to the laboratory, each of the animais was given five trials per day in the runway, with an interval of about $1 \mathrm{~h}$ between trials. For the first 3.5 days (depending on performance), each animal was carried in its house to the runway and was put down in its house about $35 \mathrm{~cm}$ from the goal end; $15 \mathrm{sec}$ later, a crab was dropped into the water at the goal end. When the animal took the crab, it was scooped up in its house and carried back to its living tank. For the next $3-6$ days (again depending on performance), the procedure was the same except that the house was put down in the middle of the runway and the crab was dropped in at the goal end after $30 \mathrm{sec}$. Then the formal trials began, the house being put down at the starting end of the runway and no crab being given until the animal had come out of its house and had traversed the entire runway. If, on any trial, the animal failed to reach the goal end in $5 \mathrm{~min}$, it was returned to its living tank.

The individual learning curves are plotted in terms of the median time per trial on each day. They fall in the manner characteristic of runway curves to an asymptote of 50-60 sec. On the 24 th day, all three curves rise sharply, because the animals refused to leave their houses on that day, and, in the following 2-3 days, all three began to produce eggs. Like vulgaris (Wood, 1963), maya females stop taking food when egg deposition is imminent. Figure 6 is a drawing made from a photograph that shows a female and her eggs in one of the plastic houses. Neither our technique of keeping the animals in the laboratory nor the runway training itself interferes, apparently, with this aspect of the reproductive process. The eggs hatch normally, and the large active young, like those of Octopus briareus described by Messenger (1963), are suitable subjects for the study of the ontogeny of behavior in the octopus, although we have as yet given no attention to the problem of how to rear the young in the laboratory.

Another traditional mammalian training situation that we found appropriate for octopuses is the simple maze. Our apparatus is diagrammed in Fig. 7. The width of the stem, the two arms, and the two end compartments is the same as that of the individual living tanks. An animal in its house is put down in the stem, and as that happens, the water in the house (which, here, has no runoff holes) spills into the arms of the maze and out into the end compartments, each of which contains another plastic house (without holes) set

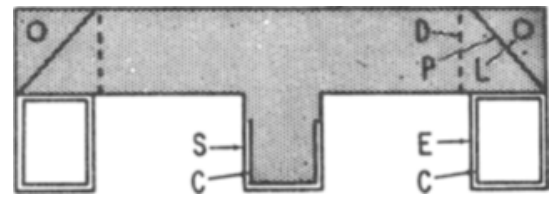

Fig. 7. A simple maze for the octopus. The gray starting compartment (S) and the two arms represent a moist surface over which the animal moves from its plastic house (C), set in the starting compartment, to one or the other of the end compartments (E), each of which contains another house $(C)$ filled with circulating sea water. A barrier permits either end compartment to be converted into a cul. An error is scored whenever any portion of the animal passes into the cul beyond the criterion line (D). Lamps (L) set behind diffusing Plexiglas panels (P) at either end provide the possibility of training the animal in a visual discrimination.

on its back and filled with circulating sea water. Since the floor of each end compartment is $17 \mathrm{~cm}$ below the arms of the maze, the level of the water in the house is approximately that of the arms. The animal leaves the stem and moves over the wet surface of the maze in one direction or another. At the ends of the arms are translucent Plexiglas panels, behind which are lamps that can be used as cues to correct choice, but in the experiment reported here, both lamps were off and the animals were trained in a spatial discrimination. The incorrect turn led to a barrier at the entrance of the end compartment on one side, while the correct turn permitted the animal to enter the water of the house in the end compartment on the opposite side, after

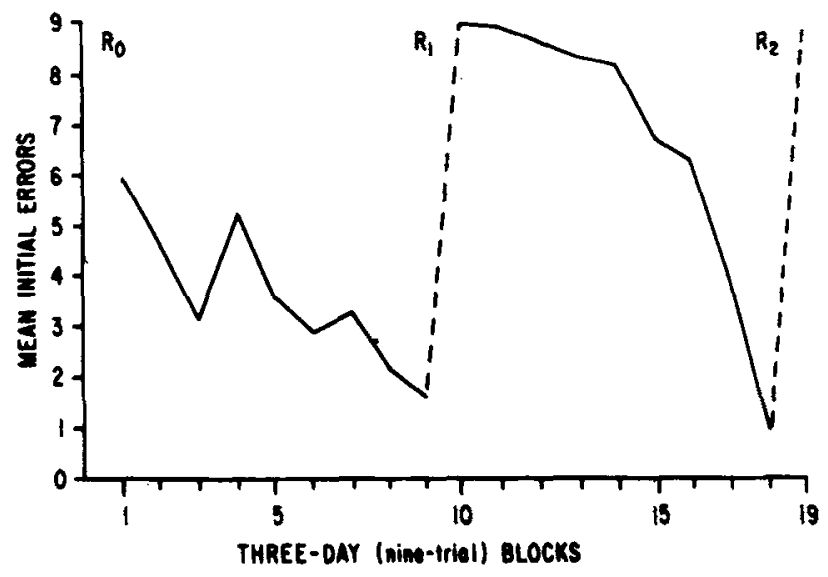

Fig. 8. Acquisition and reversal of a position preference in a group of octopuses. Since the curves are plotted in terms of the mean number of initial errors made in 3-day blocks of three trials per day, the chance level is 4.5 . $R_{0}$ is the original problem, $R_{1}$ the first reversal, and $R_{2}$ the beginning of a second reversal. 
which it was carried in that house back to its living tank. The criterion of error was the movement of any part of the animal beyond the line marked on the floor at the far end of the incorrect arm. Repetitive as well as initial errors were recorded on each trial, because it often happened that an animal would make an incorrect turn, retreat to the stem, make another incorrect turn, and so forth.

After several days of pretraining with both turns rewarded, five octopuses were trained against slight initial preferences (three to the left and two to the right). There were three trials per day for 27 days, with an intertrial interval of about $1 \mathrm{~h}$. By the 27th day, all animals were performing errorlessly, and on the 28th day, reversal training was begun (the previously correct turn now being incorrect). Beginning with the 55th day, there were 3 days of training on a second reversal. In Fig. 8, the results are plotted in terms of mean initial errors per block of 3 days. That the animals developed a preference for the side which was rewarded in the first stage of training $\left(R_{0}\right)$ is shown by the steady decline in errors during that stage and by the sharp and persistent increase in errors on the early days of the first reversal $\left(R_{1}\right)$. That the animals were capable of reversing the preference established in $R_{0}$ is shown by the steady decline of errors in $R_{1}$ and by the sharp and persistent rise in errors during the 3 days of the second reversal $\left(\mathbf{R}_{2}\right)$.

We also have made some preliminary experiments on spatial learning in this maze with the incorrect turn leading, not to a barrier, but to a house filled with fresh water. Although it has been reported that vulgaris can discriminate between fresh and salt water when pads soaked in one or the other are touched to its arms (Wells, 1963), our animals would enter the fresh water without hesitation and then, perhaps because they were already somewhat deprived of oxygen, often would become disoriented, thrash about, and not emerge before being substantially damaged. None of our animals was able to survive a series of trials under these conditions. We also have devoted a good deal of thought to the development of an appropriate manipulandum for the octopus, but none of our devices has yet proved satisfactory.

A recent paper by Nixon (1969) suggests, however, that the problem is not an insoluable one.

\section{REFERENCES}

BITTERMAN, M. E. Phyletic differences in learning. American Psychologist, 1965, 20, 396-410.

BITTERMAN, M. E., WODINSKY, J., \& CANDLAND, D. K. Some comparative psychology. American Journal of Psychology, 1958, 71, 94-110.
COATES, H. J., HUSSEY, R. E., \& NIXON, M. An automatic food dispenser for Octopus vulgaris. Journal of Physiology, 1966, 183, 51P-52P.

DILLY, N., NIXON, M., \& PACKARD, A. Forces exerted by Octopus vulgaris. Pubblicazione Stazione Zoologica Napoli, 1964, 34, 86-97.

MALDONADO, $H$. The positive learning process in Octopus vulgaris. Zeitschrift für vergleichende Physiologie, 1963, 47, 191-214.

MALDONADO, H. Effect of electroconvulsive shock (ECS) on memory in Octopus vulgaris Lamarck. Zeitschrift für vergleichende Physiologie, 1968, 59, 25-37.

MESSENGER, J. B. Behavior of young Octopus briareus Robson. Nature, 1963, 197. 1186-1187.

MUNTZ, W. R. A., SUTHERLAND, N. S., \& YOUNG, J. Z. Simultaneous shape discrimination in Octopus after removal of the vertical lobe. Journal of Experimental Biology, $1962,39,557-566$.

NIXON, M. Changes in body weight and in take of food by Octopus vulgaris. Journal of Zoology, 1966, 150, 1-9.

NIXON, M. The time and frequency of responses by Octopus vulgaris to an automatic food dispenser. Journal of Zoology, 1969. $158,475-483$.

PARRISS, J. R. Interference in learning and lesions in the visual system of Octopus vulgaris. Behaviour, 1963, 21, 233-245.

POTTS, A., \& BITTERMAN, M. E. A nunway for the fish. Behavior Research Methods \& Instrumentation, 1968, 1, 26-27.

SUTHERLAND, N. S. Visual discrimination of orientation by Octopus. British Journal of Psychology, 1957, 48, 55-71.

SUTHERLAND, N. S., \& MUNTZ, W. R. A. Simultaneous discrimination training and preferred directions of motion in visual discrimination of shape in Octopus vulgaris Lamarck. Pubblicazione Stazione Zoologica Napoli, 1959, 31, 109-126.

VOSS, G. L., \& SOLIS-RAMIREZ, M. Octopus maya, a new species from the Bay of Campeche, Mexico. Bulletin of Marine Sciences, 1966, 16, 615-625.

WELLS, M. J. Taste by touch: Some experiments with Octopus. Journal of Experimental Biology, 1963, 40, 187-193.

WELLS, M. J. Tactile discrimination of surface curvature and shape by the octopus. Journal of Experimental Biology, 1964a, 41, 433-445.

WELLS, M. J. Detour experiments with octopuses. Journal of Experimental Biology, 1964b, 41, 621-642.

WELLS, M. J., \& YOUNG, J. Z. Learning with delayed rewards in octopus. Zeitschrift für vergleichende Physiologic, 1968, 61, 103128.

WOOD, JR., F. G. Observations on the behavior of Octopus. Proceedings of the International Congress of Zoology, 1963, 73, 16.

YOUNG, J. Z. Influence of previous preferences on the memory of Octopus vulgaris after removal of the vertical lobe. Journal of Experimental Biology, 1965, 43, 594-603. NOTES

1. This research was supported by Grant GB 4501 from the National Science Foundation and by Contract Nonr 2829(01) with the Office of Naval Research. The varticipation of Dr. Longo was made possible by Grant MH 10846 from the Public Health Service and by a grant from Carter-Wallace, Inc. We are indebted to Biologo Dilio Fuentes $C$. for making the facilities of his laboratory at Campeche available for the project.

2. Another disadvantage of the traditional method is that it provides no control over the position of the animal at the start of each trial, which is necessary if the commonly used latency measure is to have any meaning. In theory, the animal should return to its house after each trial and wait there until the start of the next trial, but that often does not happen. At Naples in 1965 , one of us (Bitterman), in collaboration with W. R. A. Muntz, tested a fully automated version of the traditional procedure, which involved the use of photocells to detect the presence of the animal in its house. When the programmer was set to start a trial only if the animal was at home, not many trials were started. Most animals would come out when the apparatus was brought to their living tanks and loiter in the vicinity of the response panel. Experimental accounts are silent, for the most part, on this problem. Maldonado (1963) has used a pair of wooden pincers to push the animal back into its house at the start of a trial but now (1968) does not do so, being content merely to have a rough index of the position of the animal in the tank as determined by a set of photocelis. Wells and Young (1968) recently have reported the use of a transparent sheet of plastic to keep the animal close to its house in the intertrial interval. They admit that no "complete solution" to the problem yet has been found.

3. The earthenware pots in which the animals are caught have holes drilled in them to facilitate extraction of the animals as they are collected. A pot containing an animal is lifted into the boat without being detached from its line, the water is permitted to drain out, and then the pot is set in amall bucket of fresh water, which the animal finds aversive. As the fresh water flows into the pot through the holes, the animal comes out of the pot and is transferred by hand to well of sea water. Before building our plastic houses, we kept the animals in the laboratory in pots like those in which they had been caught, and it was then that we found that they could be carried about in their pots (which emptied as they were carried) without disturbance. The advantage of the plastic house, of course, is that (given the dimensions of the living tank) the animal can more easily be scooped in it when necessary.

4. Octopus maya will not escape from an uncovered tank after being in the laboratory for a few hours, except when it is very hungry or when it is being studied in an aversive experimental situation (involving oxygen deprivation or shock) or when the sea water is foul. It is easy to demonstrate that inadequate circulation produces climbing out. If, instead of running sea water into each of a row of five individual tanks as shown in Fig. 2, about one liter per min of sea water is supplied only to the first, and the outflow from the first supplied to the second, the outflow from the second supplied to the third, and so forth, the animal in the fifth tank soon will climb out, then the fourth, and then the third, while the first and second remain. If the water to all tanks is simply turned off, all the animals will climb out.

The laboratory lore on vulgaris is that the animal will take advantage of any opportunity to escape. The practice, before new tanks with bolted lids were introduced at Naples a few years ago, was to pile four or five heavy building bricks on the already heavy lid of each living tank, and still animals would manage to escape (for illustration, see Dilly, Nixon, \& Packard, 1964, Fig. $4 b$ ). There is a closed system of sea-water circulation in Naples, and bad water is, in our opinion, responsible for the difficulty. N.S. Sutherland reports (personal communication) that when he first began to work at Naples far tewer animals lived in the taboratory, and they could be kept in uncovered tanks. 